\title{
O Panorama do Design Sustentável nas Matrizes Curriculares dos Cursos de Design da Grande Vitória/ES e Grande Belo Horizonte/MG
}

The Panorama of Sustainable Design in the Curricular Matrices of the Design Courses of Greater Vitória / ES and Grande Belo Horizonte / MG

CAETANO, Michele Silva da Mata; Mestranda; Instituto Federal do Espírito Santo (Ifes), Faculdade do Centro Leste (UCL)

michelemata.hl@gmail.com

XAVIER, Aline Freitas da Silva; Doutoranda; Universidade do Estado de Minas Gerais (UEMG), Instituto Federal do Espírito Santo (Ifes)

alinegoval@gmail.com

ALMEIDA, Marcelina das Graças de; Doutora; Universidade do Estado de Minas Gerais (UEMG)

almeidamarcelina@gmail.com

\section{Resumo}

Este estudo tem como objetivo analisar as matrizes curriculares dos cursos de design da Grande Vitória/ES e da Grande Belo Horizonte/MG, a fim de verificar a importância dada por essas instituições ao tema sustentabilidade e suas dimensões: ambiental, social e econômica. Foi feita análise da estrutura curricular das disciplinas que abordam a sustentabilidade no site das universidades, visando diagnosticar como o tema sustentabilidade é apresentado nos cursos de design. A pesquisa revelou que poucos cursos ofertam disciplinas com essa temática, tanto nos cursos analisados no Espírito Santo quanto nos de Minas Gerais. Na Grande Vitória, apenas dois dos sete cursos analisados têm disciplinas sobre o tema; já na Grande Belo Horizonte, seis dos treze cursos abordam o tema.

Palavras Chave: design sustentável; ensino; sustentabilidade; design.

\section{Abstract}

This study aims to analyze the curricular matrices of design courses in Grande Vitória / ES and Grande Belo Horizonte / MG, in order to verify the importance of these institutions to sustainability and its environmental, social and economic dimensions. It was carried out the survey of the curricular structure of the disciplines that approach sustainability, through the university website, aiming to diagnose how the sustainability approach in design courses occurs. The research revealed that there are few courses that offer subjects related to this subject, both in the courses analyzed in Espirito Santo and in Minas Gerais. In Greater Vitória, only two of the seven courses analyzed have disciplines on the subject; already in the great Belo Horizonte, six of the thirteen courses approach the theme.

Keywords: sustainable design; teaching; sustainability; design. 


\section{Introdução}

Este artigo apresenta a importância de discutir assuntos relacionados ao tema sustentabilidade pelas instituições de ensino superior que ofertam cursos de design na grande Vitória - Espírito Santo (ES) e na grande Belo Horizonte (BH) - Minas Gerais (MG), considerando a oferta ou não de disciplinas com esse tema.

Para isso, descreve-se a investigação realizadas nos websites de dez instituições que ofertam cursos nesses dois Estados, a fim de entender como funcionam os cursos e como estão estruturados, segundo suas matrizes curriculares, bem como se possuem ou não disciplinas relacionadas à sustentabilidade e seus desdobramentos.

Segundo Freire (2009), um dos papéis das instituições de ensino é, além de encorajar o pensamento crítico, fomentar a argumentação e a reflexão, ensinando e não transferindo conhecimento, mas criando possibilidades para construí-lo. Ter essa visão crítica é indispensável para o designer, pois é preciso, além de compreender o que é sustentabilidade, atuar de forma holística, transversal e sistêmica, tendo o design sustentável como eixo central do projeto.

Nesse sentido, ter disciplinas norteando a temática sustentabilidade nas matrizes curriculares de cursos de design é fundamental para estimular e promover uma formação consciente e ética a respeito da sustentabilidade.

O conceito de desenvolvimento sustentável foi abordado pela primeira vez na Conferência Intergovernamental pelo Uso Racional e Conservação da Biosfera, da Organização das Nações Unidas para Educação, Ciência e Cultura (UNESCO), com a seguinte definição: "desenvolvimento capaz de suprir as necessidades da geração atual, sem comprometer as gerações futuras, englobando soluções que unem o economicamente viável ao ecologicamente correto e socialmente equitativo." Esse conceito foi a base para a Conferência das Nações Unidas pelo Desenvolvimento e Meio Ambiente (UNCED), a Eco-92, que ocorreu no Rio de Janeiro em 1992, sendo referência relevante do Quinto Plano de Ação da União Europeia para o Ambiente.

No atual contexto mundial, complexo e diversificado, torna-se significativo aliar a sustentabilidade com o design, sendo imprescindível, contudo, observar seus preceitos ao desenvolver produtos e/ou serviços, pois, desse modo, poderão causar menos danos ao planeta. Desta maneira, para que os designers possam inserir em seus projetos cuidados e se atentar para a sustentabilidade, devem adquirir conhecimentos e possuir subsídios para tal. Sendo assim, o presente trabalho aborda a inserção de questões relacionadas à sustentabilidade em cursos de graduação em design de Instituições da Grande Vitória/ES e na Grande Belo Horizonte/MG.

\section{Metodologia}

O desenvolvimento da pesquisa consistiu em duas etapas, mas antes de descrevê-las, vale destacar que a escolha por esses dois Estados é porque não pertencem ao eixo Rio - São Paulo, no qual se encontram as escolas de design que, normalmente, figuram nos livros de história do design e são objeto de estudos de diversas pesquisas.

A primeira etapa da pesquisa foi identificar, pela internet, quantos são e quais instituições ofertam o curso de design em ambos os Estados. Em um segundo momento, nos websites das dez instituições encontradas nesses dois estados, realizou-se uma pesquisa para entender como funcionam os cursos e como estão estruturados segundo suas matrizes curriculares, bem como se possuem ou não disciplinas relacionadas com a sustentabilidade e seus desdobramentos. Foram 
analisadas as matrizes curriculares de vinte e cinco cursos de design, sendo eles das seguintes habilitações: seis - Produto; sete - Gráfico; quatro - Interiores; seis - Moda; um - Construção; um Ambientes.

Procedeu-se, assim, à análise das matrizes curriculares que têm disciplinas direcionadas ou que abordam o ensino de questões da sustentabilidade no design, sendo coletados dados referentes à denominação da disciplina, se é obrigatória ou optativa, o período de oferta e a carga horária.

\section{O Ensino do Design e a Sustentabilidade}

Segundo o Diagnóstico do Design Brasileiro publicado em 2014, o Brasil tinha 538 cursos de graduação no ano de 2012, conforme mostra a Figura 1.

Figura 1 - Distribuição dos cursos de graduação na área de design ofertados no Brasil

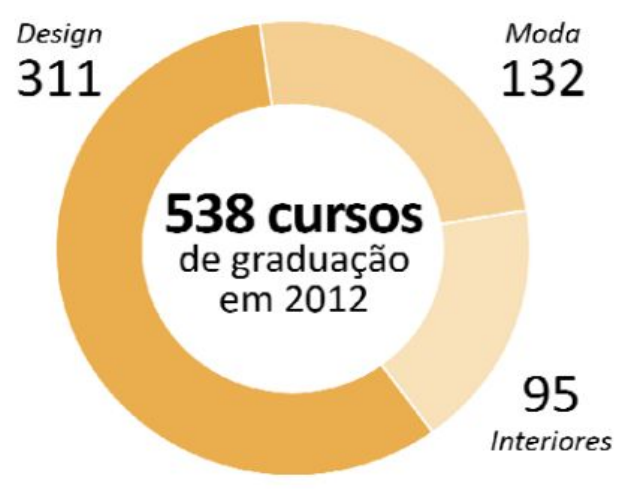

Fonte: INEP (2012) apud BRASIL (2014)

Esses 538 cursos são ofertados por 267 instituições, sendo que $21 \%$ delas são públicas e os outras $79 \%$ são privadas (Figura 2 ). 
Figura 2 - Instituições Públicas e Privadas

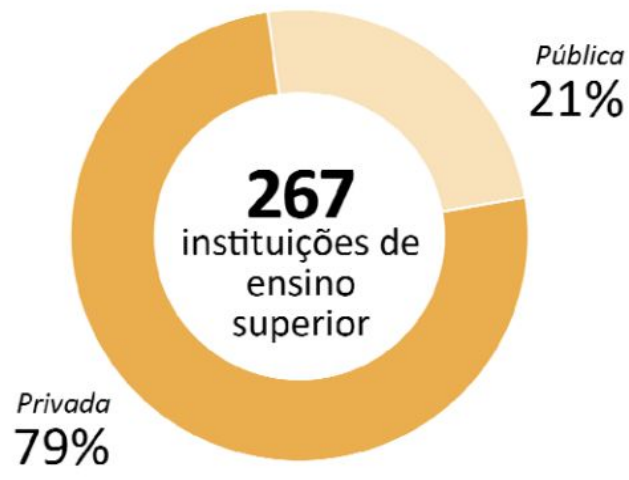

Fonte: INEP (2012) apud BRASIL (2014)

As temáticas abordadas pelas escolas de design acerca do ensino do desenvolvimento sustentável estão relacionadas ao redesign dos produtos, às soluções End-of-Pipe, à análise do ciclo de vida (Life Cicle Design), à desmaterialização e à avaliação sistêmica de todo o processo com o Product Service System - PSS (Sistema Produto Serviço). Essa abordagem, segundo Mourão et al. (2010), torna a atuação do design holística, transversal e sistêmica, visto que busca soluções para os problemas complexos do meio ambiente ao propor reflexões e debates sobre as mudanças nas formas de pensar, visando compreender a formação dos objetos culturais contemporâneos e a educação ambiental.

Campo essencialmente híbrido, que opera a junção entre corpo e informação, entre artefato, usuário e sistema (CARDOSO, 2012), o design para a sustentabilidade articula requisitos sociais, econômicos e ambientais. A função estética, nesse contexto, está mais diretamente ligada à ética, entendida neste estudo no sentido de comportamento coletivo social (MORAES, 2009).

Essa forma de pensar o viver sustentável e sua relação com o design foi proposta inicialmente por Papanek, com o propósito de refletir sobre como o homem poderia reduzir os impactos e suas ações no planeta, modalidade intitulada como ecodesign. Segundo Kazazian (2005), o ecodesign é parte de um processo que busca tornar a economia mais "leve".

O paradigma do mundo complexo vivenciado pelos profissionais de design, outrora responsabilizados pelo consumo e pela utilização de uma estética cosmética e descartável, precisa ser desconstruído. Daí a necessidade de esses profissionais repensarem o desenvolvimento dos produtos com responsabilidade no processo do desenvolvimento econômico social e ambiental e assim, assegurar o direito ao desenvolvimento e às condições de vida equilibrada e sadia, tanto para a geração atual como para as gerações futuras.

E como pensar o design para a sustentabilidade nas instituições de ensino considerando todos esses aspectos? Se, para "Projetar solução para um mundo complexo passa por aceitar a complexidade como precondição em vez de combatê-la"? (CARDOSO, 2012, p. 230). Entre teoria e prática, a grande importância do ensino do design para a sustentabilidade reside, hoje, precisamente, em sua capacidade de construir pontes e forjar relações em um mundo cada vez mais esfacelado pela especialização e fragmentação dos saberes (CARDOSO, 2012).

\section{Análise das Matrizes Curriculares}


Foram pesquisadas as matrizes curriculares de vinte e cinco cursos de nove instituições, sendo sete cursos da Grande Vitória - Espírito Santo, e treze de Belo Horizonte - Minas Gerais.

Os temas relativos à sustentabilidade ainda são incipientes nas matrizes curriculares dos cursos de design no Brasil, a inclusão como assunto relevante nas disciplinas é muito recente, e seu foco restringe-se ao ecodesign e à minimização do impacto ambiental dos processos produtivos (FONTOURA; SAMPAIO, 2007).

\subsection{Matrizes Curriculares dos Cursos da grande Vitória - Espírito Santo}

A Universidade Federal do Espírito Santo (UFES) ${ }^{1}$ oferece o Bacharelado em Design Gráfico, ainda denominado Desenho Industrial. Criado há mais de 10 anos, suas disciplinas estão distribuídas em nove períodos, o que equivale a quatro anos e meio de curso. Os quatro primeiros períodos estão organizados em uma carga horária de duzentas e setenta horas cada, e os quatro últimos variam de noventa a cento e vinte horas cada. O currículo contempla trinta e três disciplinas obrigatórias e duas optativas, sendo o projeto de graduação obrigatório e previsto para ser elaborado em duas etapas.

As discussões e os trâmites necessários para reformular a matriz curricular do curso iniciaram-se aproximadamente em meados de 2006. Naquele ano, já eram discutidas questões relacionadas ao design sustentável, mas, mesmo assim, a matriz curricular vigente ainda não contempla nenhuma disciplina com essa temática. Assim, os alunos e os egressos desse curso precisam buscar informações sobre esse tema por conta própria ou em eventuais programas de extensão oferecidos pela instituição.

A Faculdade do Centro Leste (UCL), situada no município de Serra, iniciou a oferta do curso de bacharelado em Design de Produto em 2001 e, posteriormente, passou a ofertar dois cursos de Tecnólogo em Design, um com habilitação em design gráfico, e outro em design de produto. 0 curso está estruturado em quatro períodos, com seis disciplinas em cada um deles. Os dois primeiros períodos possuem disciplinas em comum nos dois cursos e, a partir do terceiro período, o aluno pode escolher qual habilitação deseja seguir, design gráfico ou produto. No terceiro período de ambas as habilitações, a matriz curricular contempla a disciplina denominada design sustentável. A presença dessa disciplina na matriz curricular do curso é fundamental para a formação dos alunos e dos egressos, já que o tema design sustentável é relevante para essa formação, pois o conhecimento sobre o tema se torna uma oportunidade para refletir acerca da situação dos projetos que poderá desenvolver com questões ligadas à sustentabilidade.

Para essa formação, a incorporação desse conhecimento pelo contato com o tema design sustentável já durante a graduação, certamente, facilitará a interiorização e a conscientização da temática, já que, como profissional no mercado de trabalho e durante o desenvolvimento de seus projetos, esse tema estará sempre presente nas ideias e pensamentos.

Outra instituição que oferece curso de design é a Faculdade Espírito-Santense (FAESA), oferecendo os cursos de bacharelado em Design de Moda e Vestuário ${ }^{3}$ e Design de Interiores ${ }^{4}$. Ambos os cursos têm duração de seis períodos, sendo que Design de Interiores tem em sua matriz curricular quarenta e duas disciplinas, e Design de Moda e Vestuário conta com quarenta e uma

\footnotetext{
${ }^{1}$ Disponível em <http://www.ufes.br/> Acesso em: 4 jan. 2018

${ }^{2}$ A última oferta do curso de Design da UCL foi em 2015/1.

${ }^{3}$ Disponível em: <https://www.faesa.br/curso/design-de-moda-e-vestuario > Acesso em: 28 mar. 2018.

${ }^{4}$ Disponível em: <https://www.faesa.br/curso/design-de-interiores> Acesso em: 28 mar. 2018.
} 
disciplinas. No curso de Design de Moda e Vestuário não existe nenhuma disciplina relacionada à temática da sustentabilidade, porém, no curso de Design de Interiores há, no segundo período do curso, a disciplina Conforto Ambiental: Sustentabilidade e Fundamentação.

A Universidade de Vila Velha ${ }^{5}$ oferece os cursos Tecnólogo em Design de Produto e Design de Moda, ambos com duração de dois anos e meio. O curso de Design de Produto tem uma carga horária de mil novecentas e vinte horas, distribuídas em vinte e quatro disciplinas, sendo vinte e duas obrigatórias e duas optativas. O curso de Design de Moda possui vinte e nove disciplinas, todas obrigatórias, totalizando mil oitocentos e oitenta horas. Nenhuma dessas formações contempla na matriz curricular uma disciplina com questões envolvendo sustentabilidade.

Com as análises das matrizes curriculares desses cursos oferecidos na Grande Vitória, pode-se perceber que a maioria das instituições de ensino que oferta curso de design não contempla em seus currículos disciplinas atentas à temática da sustentabilidade e do papel estratégico do design na discussão.

Essa significativa carência de práticas educativas, as quais pedem propostas pedagógicas centradas na conscientização, na mudança de comportamento, no desenvolvimento de competências, na capacidade de avaliação e participação dos educandos, representa uma grande oportunidade para um repensar das instituições de ensino superior em Design. O objetivo, assim, deve ser no sentido de investir na formação de sujeitos sintonizados com as necessidades ambientais, econômicas e sócioéticas, além de apoiar e consolidar o desenvolvimento de metodologias e material didático para um ensino crítico e participativo do design e dos requisitos sustentáveis (FONTOURA; SAMPAIO, 2007).

Porém, como o design sustentável é um tema presente em inúmeras publicações e discutido em eventos da área, é possível que os alunos e egressos desses cursos já tenham tido contato com a temática e até utilizado esse contexto durante a elaboração de seus projetos. Todavia, essa situação ainda não é a ideal para a área, pois o profissional precisa ter contato com o tema no início de sua formação, nesse caso, na graduação, e não apenas em especializações e eventos.

\subsection{Matrizes Curriculares dos Cursos da Grande Belo Horizonte}

A Universidade Federal de Minas Gerais (UFMG) ${ }^{6}$ oferece os cursos de Design de Moda (Escola de Belas Artes), Design de Produto, Design Gráfico e Design para a Construção (Escola de Arquitetura).

O curso de Design de Moda é oferecido pela Escola de Belas Artes e está dividido em oito períodos, com trezentas horas cada, distribuídas entre disciplinas obrigatórias, optativas e eletivas, sendo que nenhuma delas contém temas relacionados à sustentabilidade.

Os cursos de design oferecidos pela Escola de Arquitetura estão divididos em nove períodos, em um total de duas mil e setecentas horas cada curso. Ambos os cursos possuem uma disciplina optativa denominada ecodesign e meio ambiente, de 45 horas/aula.

A Escola de Design da Universidade Estadual de Minas Gerais (ED-UEMG) ${ }^{7}$ oferece os cursos Design Gráfico, Design de Produto e Design de Interiores. Os cursos estão divididos em oito

\footnotetext{
${ }^{5}$ Disponível em: <http://www.uvv.br/graduacao/design> Acesso em: 18 mar. 2018.

${ }^{6}$ Disponível em: <https://ufmg.br/cursos/graduacao/2394/77515 > Acesso em: 22 mar. 2018.

${ }^{7}$ Disponível em: <http://www.ed.uemg.br/cursos/> Acesso em: 20 mar. 2018.
} 
períodos, com trezentos e vinte horas cada, com disciplinas de caráter obrigatório que totalizam duas mil quinhentas e sessenta horas, sendo de caráter complementar cento e noventa e duas horas para os cursos de Design Gráfico e Produto, e seiscentos e quarenta e quatro horas para o curso de Design de Ambientes. Contudo, nenhuma das disciplinas distribuídas nessas cargas horárias é especificamente sobre o tema debatido neste artigo.

A Fundação Mineira de Educação e Cultura (FUMEC) ${ }^{8}$ oferece os cursos Design e Design de Moda. O curso de Bacharelado em Design articula as diferentes áreas do design: gráfico, interiores e produto.

O curso de Design tem duração de oito períodos, com uma carga horária total de duas mil seiscentas e oitenta horas. No terceiro período, o aluno tem a disciplina obrigatória Design para a Sustentabilidade, com carga horária de 40h/aula.

O curso de Design de Moda divide-se em oito períodos, e busca capacitar o aluno para produzir projetos que envolvam sistemas de informações visuais, artísticas, estéticas, culturais e tecnológicas, assim como elaborar conceitos, planejar e desenvolver alternativas de projetos para diversas categorias de produtos das áreas do design, visto que conhece diversos processos de fabricação disponíveis no mercado. Para isso, a carga horária de disciplinas do curso totaliza duas mil e novecentas e quarenta horas, das quais sessenta horas estão relacionadas ao tema moda e sustentabilidade, e está disponível no quinto período do curso.

O Centro Universitário UNA ${ }^{9}$ oferece as seguintes habilitações em Design: Interiores e Gráfico. Essas duas habilitações são de graduação tecnológica, têm duração de quatro semestres, totalizando duas mil duzentas e dezesseis horas. Nenhuma das matrizes curriculares dos cursos de design dessa instituição tem disciplinas sobre o tema sustentabilidade.

O Centro Universitário Belo Horizonte (UniBH) oferece os cursos Tecnólogo em Design Gráfico (dois anos de duração) e Bacharelado em Design (quatro anos de duração). O curso de Design Gráfico tem carga horária total de mil seiscentas e oitenta horas, e não contempla nenhuma disciplina com o tema sustentabilidade. Já o curso de bacharelado em Design tem carga horária total de duas mil quatrocentos e oitenta horas, sendo que $80 \mathrm{~h} /$ aula destinam-se à disciplina Design Sustentável, ofertada no terceiro período do curso.

\section{Comparativo entre a situação Capixaba e a Belorizontina}

O objetivo deste estudo foi apresentar a situação atual dos temas relacionados à sustentabilidade, tanto na Grande Vitória quanto na Grande Belo Horizonte. Ambos os Estados já vêm construindo, há alguns anos, uma história importante referente ao ensino do design, principalmente Minas Gerais, pelos seus mais de sessenta anos de ensino de design.

A hoje denominada UEMG foi criada em 1955 com o nome de Escola de Artes Plásticas, subordinada à já existente Escola de Música da UMA (Universidade Mineira de Arte - Fundação Educacional). Por sua vez, a UMA foi inaugurada em 1954 como resultado da associação de outras três instituições: Sociedade Coral, Cultura Artística, e Orquestra Sinfônica de Minas Gerais. Em 1956, a Escola de Artes Plásticas elaborou um curso preparatório, realizou seu primeiro vestibular e começou a funcionar plenamente em 1957, com sua primeira turma de alunos.

Ambos os Estados estão sendo analisados neste artigo porque não pertencem ao eixo Rio -

\footnotetext{
${ }^{8}$ Disponível em: <http://vestibular.fumec.br/cursos/presencial/graduacao/design/> Acesso em: 25 mar. 2018.

${ }^{9}$ Disponível em: <https://www.una.br/cursos/graduacao/> Acesso em: 21 mar. 2018.
} 
São Paulo, no qual se encontram as escolas de design que normalmente figuram nos livros de história do design e que servem de objeto de estudos para diversas pesquisas.

Quadro 1 - Comparação dos dados da Grande Vitória e da Grande Belo Horizonte

\begin{tabular}{|c|c|}
\hline Vitória & Belo Horizonte \\
\hline 7 cursos analisados & 13 cursos analisados \\
\hline Gráfico (2) & Gráfico (4) \\
\hline Produto (2) & Produto (2) \\
\hline Interiores (1) & Interiores (2) \\
\hline \multirow[t]{3}{*}{ Moda (2) } & Moda (2) \\
\hline & Bacharelado (2) \\
\hline & Construção (1) \\
\hline 4 Instituições de ensino analisadas & 5 Instituições de ensino analisadas \\
\hline $\begin{array}{l}2 \text { cursos com disciplinas que abordam o } \\
\text { tema sustentabilidade }\end{array}$ & $\begin{array}{l}6 \text { cursos com disciplinas que abordam o tema } \\
\text { sustentabilidade }\end{array}$ \\
\hline
\end{tabular}

Fonte: adaptado de edital P\&D 2018 (2017)

Foram analisadas as matrizes curriculares de nove instituições de ensino superior que oferecem cursos de design em diversas habilitações, sendo quatro na Grande Vitória, e cinco na Grande Belo Horizonte. No caso da Grande Vitória, essas são as únicas instituições com esse curso, já no caso de Belo Horizonte, foram selecionadas as cinco mais expressivas. No total, foram sete cursos analisados no Espírito Santo e treze cursos em Minas Gerais.

\section{Considerações Finais}

É preciso o envolvimento e o compromisso das instituições de ensino que oferecem cursos de design para estimular o acesso ao tema sustentabilidade pelos alunos, bem como fazer com que ele permaneça constantemente nos pensamentos, ideias, trabalhos, projetos, etc. do futuro profissional de design, pois é um tema bastante relevante e contemporâneo, conforme discutido neste artigo.

Por meio de análises das matrizes curriculares foi possível perceber que poucos cursos disponibilizam para seus alunos disciplinas com o tema analisado: na Grande Vitória, apenas dois dos sete cursos analisados têm disciplinas sobre o tema; já na Grande Belo Horizonte, seis dos 13 cursos abordam o tema.

A importância de ofertar disciplinas sobre sustentabilidade ou qualquer outro tema atual e 
relevante para a profissão enriquece a formação e se torna um diferencial. Com elas, o aluno e futuro profissional estará sempre atualizado e se sentirá mais preparado para inserir em seus projetos aspectos sustentáveis, de forma econômica, social e ambiental.

Designers, como aqueles que usam a criatividade na proposição de soluções, devem assumir um papel de liderança, incentivando o uso responsável dos recursos. Isso envolve tanto o conceito tradicional de sustentabilidade como também uma compreensão das tecnologias e recursos adequados para utilização nas propostas. Resultados responsáveis incorporam questões éticas, necessidades sociais, imperativos globais e a contribuição única do Design Thinking (Brasil, 2014, p. 90).

Este artigo apresentou sucintamente como é importante manter atualizadas as matrizes curriculares dos cursos de design, porém, enquanto não for possível, que sejam inseridas paliativamente, isto é, que os alunos possam ter acesso às informações atuais discutidas na profissão por outros meios, que não a disciplina formal.

Dessa forma, como proposta futura para novas pesquisas, sugere-se ampliar o leque de discussões abrangendo os cursos ofertados em outras regiões do país e até outros temas tão importantes como este.

\section{Referências}

BRUNDTLAND, G. H. Our Common Future: World Commission on Environment and Development. Oxford: Oxford University Press, 1987.

CARDOSO, Rafael. Design para um mundo complexo. São Paulo: Cosac Naify, 2012. 263 p.

FREIRE, Paulo. Pedagogia da Autonomia: saberes necessários à prática educativa. 40ạ reimpressão. São Paulo: Paz e Terra, 2009.

MANZINI, E. \& VEZZOLI, C. O desenvolvimento de produtos sustentáveis: os requisitos ambientais dos produtos industriais. São Paulo: Edusp, 2002.

MORAES, Dijon de; FIGUEIREDO, Clarice. Ética e estética na produção industrial: caminhos possíveis para o design do novo século. Cadernos de Estudos Avançados em Sustentabilidade. Belo Horizonte, v.I. p.39-46. 2009.

SCHNEIDER, Beat. Design uma introdução: o design no contexto social, cultural e econômico. São Paulo: Blucher, 2010. 299 p.

SACHS, Ignacy. Estratégias de transição para o século XXI: desenvolvimento e meio ambiente. São Paulo: Ed. Nobel, 1993.

SILVA, Jucelia S. G. Uma experiência no ensino de design de sistemas orientados à sustentabilidade. 
KAZAZIAN, T. Haverá a idade das coisas leves: design e desenvolvimento sustentável, São Paulo: Ed. SENAC, 2005.

\section{Sites}

Faesa. Disponível em: <https://www.faesa.br/curso/design-de-moda-e-vestuario > Acesso em: 28 mar. 2018.

Faesa. Disponível em: <https://www.faesa.br/curso/design-de-interiores $>$ Acesso em: 28 mar. 2018.

FUMEC. Disponível em: <http://vestibular.fumec.br/cursos/presencial/graduacao/design/> Acesso em: 25 mar. 2018.

UCL. Disponível em <http://www.ucl.br/> acesso em: 5 jun. 2015.

UEMG. Disponível em: <http://www.ed.uemg.br/cursos/> Acesso em: 20 mar. 2018.

Ufes. Disponível em <http://www.ufes.br/> acesso em: 4 jan. 2018.

UFMG. Disponível em: <https://ufmg.br/cursos/graduacao/2394/77515> Acesso em: 22 mar. 2018.

UNA. Disponível em: <https://www.una.br/cursos/graduacao/> Acesso em: 21 mar. 2018. UniBH. Disponível em<http://www.unibh.br/> acesso em: 5 mar. 2018.

UVV. Disponível em: <http://www.uvv.br/graduacao/design> Acesso em: 18 mar. 2018. 